CARNETS OE Carnets de géographes

GÉOGRAPHES.

2| 2011

Espaces virtuels

\title{
Migrations forcées dans le sud du Brésil
}

Les Atingidos

Guillaume Leturcq

(2) OpenEdition

Journals

Édition électronique

URL : http://journals.openedition.org/cdg/2929

DOI : $10.4000 /$ cdg. 2929

ISSN : 2107-7266

Éditeur

UMR 245 - CESSMA

Référence électronique

Guillaume Leturcq, «Migrations forcées dans le sud du Brésil », Carnets de géographes [En ligne],

2 | 2011, mis en ligne le 02 mars 2011, consulté le 07 mai 2019. URL : http://journals.openedition.org/ cdg/2929; DOI : $10.4000 /$ cdg.2929

Ce document a été généré automatiquement le 7 mai 2019.

\section{(c) (†)}

La revue Carnets de géographes est mise à disposition selon les termes de la Licence Creative Commons Attribution - Pas d'Utilisation Commerciale - Pas de Modification 4.0 International. 


\title{
Migrations forcées dans le sud du Brésil
}

\author{
Les Atingidos
}

Guillaume Leturcq

1 Le principal objectif de cette recherche est l'analyse des modifications d'espaces de vies suite à des migrations forcées, dans un cadre rural sud-américain. Le Brésil est un pays marqué par de grandes vagues migratoires internes et externes. Depuis les années soixante, une forme nouvelle de migration interne émerge avec la construction de grands barrages hydroélectriques. La construction et l'installation d'un grand barrage hydroélectrique perturbent profondément les sociétés rurales, notamment dans le Sud du Brésil au tournant du siècle.

2 Les atingidos, les familles victimes des barrages du fleuve Uruguay se caractérisent par une population historique (indiens et caboclos) métissée par une colonisation européenne tardive datant d'environ 150 ans. Les populations atingidas doivent se réapproprier un espace de vie suite à leur déplacement forcé.

3 Dans ce sens, la thèse étudie les relations entre espaces et sociétés, à savoir les relations et connexions existant entre l'ouvrage et les familles vivant à proximité. L'appréhension de ces relations s'est basée sur l'étude de deux barrages construits sur le fleuve Uruguay, frontière entre les deux états du Santa Catarina (au nord) et du Rio Grande do Sul (Sud). Étudiés à deux moments distincts de leur construction, ils permettent de mieux analyser le processus migratoire. Ainsi, il a été possible d'aborder les familles avant et après les migrations, car pour le barrage de Foz do Chapecó les populations étudiées n'avaient pas encore migré, alors que pour le barrage de Machadinho, les mouvements de populations dataient déjà de plus de cinq ans. En comparant les situations et espaces de vie des populations, l'éclairage sur les altérations subies est beaucoup plus concret.

4 Les processus d'éviction et d'indemnisation et les mécanismes migratoires placent les familles dans des situations de vulnérabilité lorsqu'elles doivent s'adapter à de nouveaux territoires, où les interrelations sociales sont à reconstruire. Face à ces évolutions, les inégalités sociales sont mises en évidence et expliquent en partie les processus d'installation, manifestés sous trois formes: l'adaptation au nouveau cadre rural et 
communautaire; l'insertion dans la nouvelle structure administrative et à ses aménagements; et le maintien de liens avec l'ancien lieu de vie.

La vulnérabilité des familles n'est pas forcément le principal facteur explication de leur stabilité sur leur nouvel espace de vie. Certaines, grâce à une adaptation réussie, se stabilisent et aident à l'établissement de nouvelles communautés ou nouveaux centres ruraux. D'autres familles n'arrivant pas à perdurer sur leur nouvel espace hésitent entre une stabilité douloureuse ou une nouvelle migration tout aussi incertaine (migration de retour, migration vers les centres économiques du pays, front pionniers, etc.)

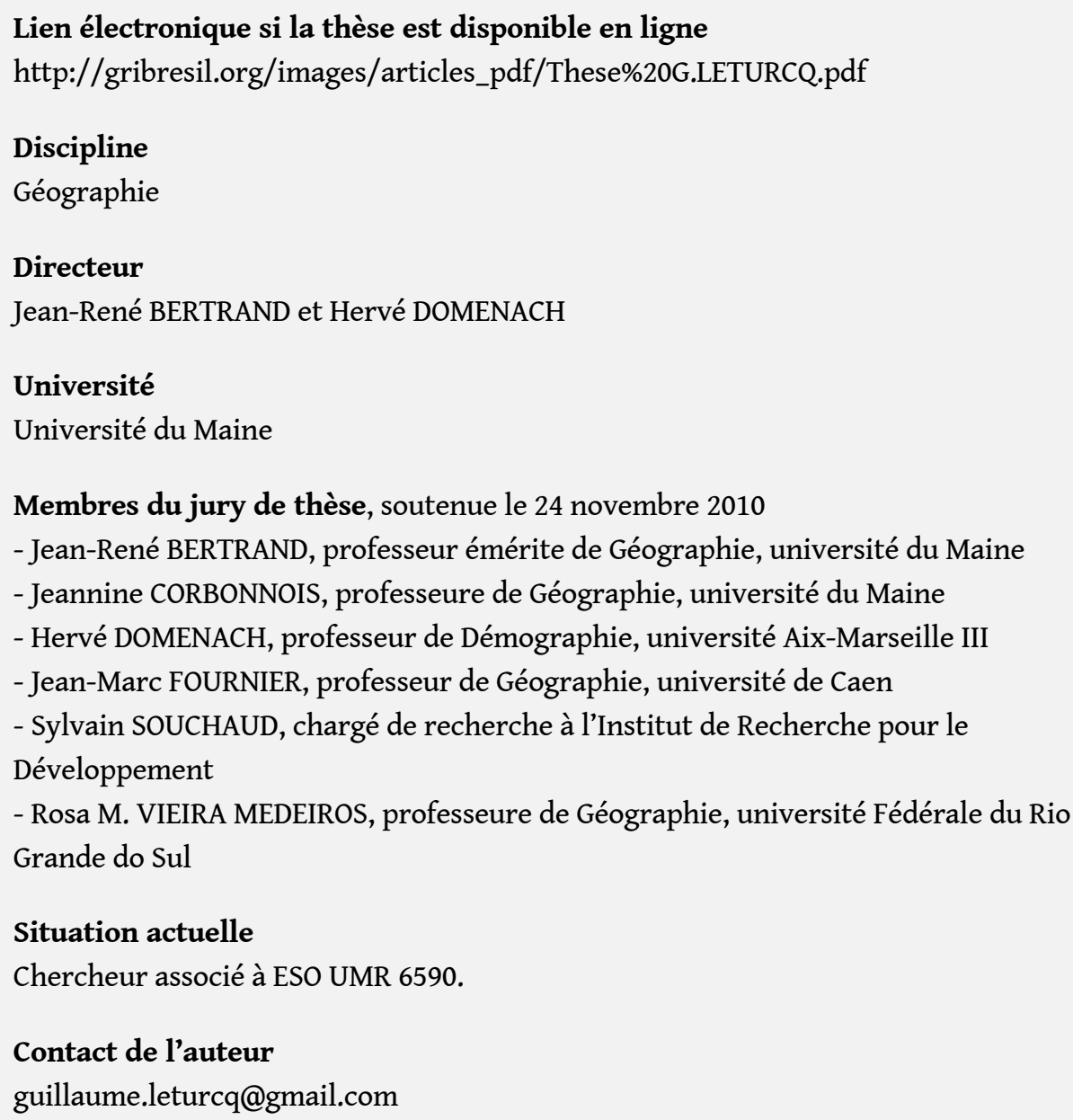

INDEX

Thèmes : Carnets de soutenances 